\title{
OXYGEN POISONING IN MICRO-ORGANISMS AND ITS RELATION TO THE TOXICITY OF OXYGEN AT HIGH PRESSURE ON MAMMALIAN TISSUE
}

\author{
JOHN W. BEAN \\ Department of Physiology, University of Michigan, Ann Arbor
}

ONE FIGURE

In the acute oxygen poisoning of vertebrates the toxicity of oxygen at high pressures, aside from its relatively minor influence on pulmonary epithelium in these short exposures, may be attributed to two effects. The first and in all probability the most outstanding action of oxygen at high pressures on these organisms dependent upon blood haemoglobin, is an interference with the normal reduction of this pigment at the tissues and a consequent inadequacy of base liberated for the carriage of carbon dioxide by the blood. This interference in turn leads to an accumulation of carbon dioxide, an increased hydrogen ion concentration of the tissues and blood, and accounts for many of the reactions seen in the animals exposed to oxygen at the high pressures (Gesell, '23; Bean, '29, '31). The second and more direct action of oxygen at high pressure on living tissue, quite aside from the disturbance in the carriage of carbon dioxide, has been clearly demonstrated by the results of experiments on isolated tissue (Bean and Bohr, '38). This direct action of oxygen at high pressure is one which apparently alters the oxidative processes of the cell by poisoning respiratory enzymes. In view of this direct action on tissue cells the effects of oxygen at similarly high barometric pressures on more primitive forms of cells is of interest because of the possible helpful information which might be derived therefrom in attempts to explain more fully the oxygen poisoning in higher forms.

The experiments herein reported were undertaken then primarily as an attempt to uncover further information which might be of value in the interpretation of the direct action of oxygen at high pressures on the respiratory mechanism of mammalian tissue. The organism employed was pneumococcus type I. This was chosen not only because of its availability but also because it possesses some features in common with anaerobic organisms-particularly a low susceptibility to any action of cyanide. This point is especially pertinent because oxygen 
at high pressures apparently impairs oxidations of isolated smooth muscle to a degree which approximates an actual anoxia. In fact the reaction of rabbit intestine to this oxygen poisoning is so very similar to that induced by cyanide administration as to suggest that high oxygen pressure and cyanide have a common site of action in the respiratory enzyme system of this tissue. If this be true, oxygen at high pressure should mimic the effects of cyanide on other cells. Now it so happens that pneumococcus is one organism which is apparently not affected to any degree by cyanide and if oxygen at high pressure simply mimics cyanide, one should expect that this organism would show little or no effect of exposure to oxygen at high pressure. The literature contains considerable data concerning the effects of increased percentage of oxygen at atmospheric pressure and also some concerning the effects of oxygen at high pressures on various organisms; but it appears no study has been made heretofore concerning the effects of oxygen at high pressure on pneumococcus.

In this study the organisms were exposed to oxygen at high barometric pressures in a compression chamber, the temperature of which was maintained at $37^{\circ}-38^{\circ} \mathrm{C}$. In order to prevent undue drying, the oxygen used in compression was bubbled through distilled water, and an open basin of water was placed inside the chamber. Control plates were kept in air at $37^{\circ}-38^{\circ} \mathrm{C}$. at atmospheric pressure. To provide a small partial pressure of carbon dioxide-a condition which exerts some beneficial influence on aerobic organisms-(Rockwell, '23; Soule, '28) the compression chamber was not washed free of room air before compression with oxygen was begun. In this way the partial pressures of carbon dioxide and nitrogen were maintained at that of room air throughout the exposures.

\section{RESULTS}

In the first series of experiments the plates were richly seeded with pneumococcus type I and exposed to an oxygen pressure of $3650 \mathrm{~mm}$. $\mathrm{Hg}$, which with the nitrogen and carbon dioxide of the room air left in the chamber made a total barometric pressure of approximately 4250 $\mathrm{mm} . \mathrm{Hg}$. On examination of these heavily seeded plates at the end of a 24-hour exposure to the high pressure it was found that all growth had been completely inhibited. The comparison of one of these plates with the luxuriant growth on a control plate (in room air at atmospheric pressure) is shown in figure $1, A$ and $B$.

In order to determine whether these organisms which had failed to show any growth during the exposure to the oxygen at high pressure, 
were still viable after such treatment, a number of the test plates which showed no growth as a result of exposure to high oxygen, were placed under the control conditions, viz. in room air at $38^{\circ}$ for 24 hours. At the end of this period one of two plates showed no growth whatsoever; the second contained only a few scattered colonies. It would appear then that the exposure of pneumococcus type I to oxygen at $3650 \mathrm{~mm}$. II $\mathrm{g}^{\mathrm{r}}$ not only completely inhibited all growth for the duration of such exposure but also killed the greater number of the organisms.
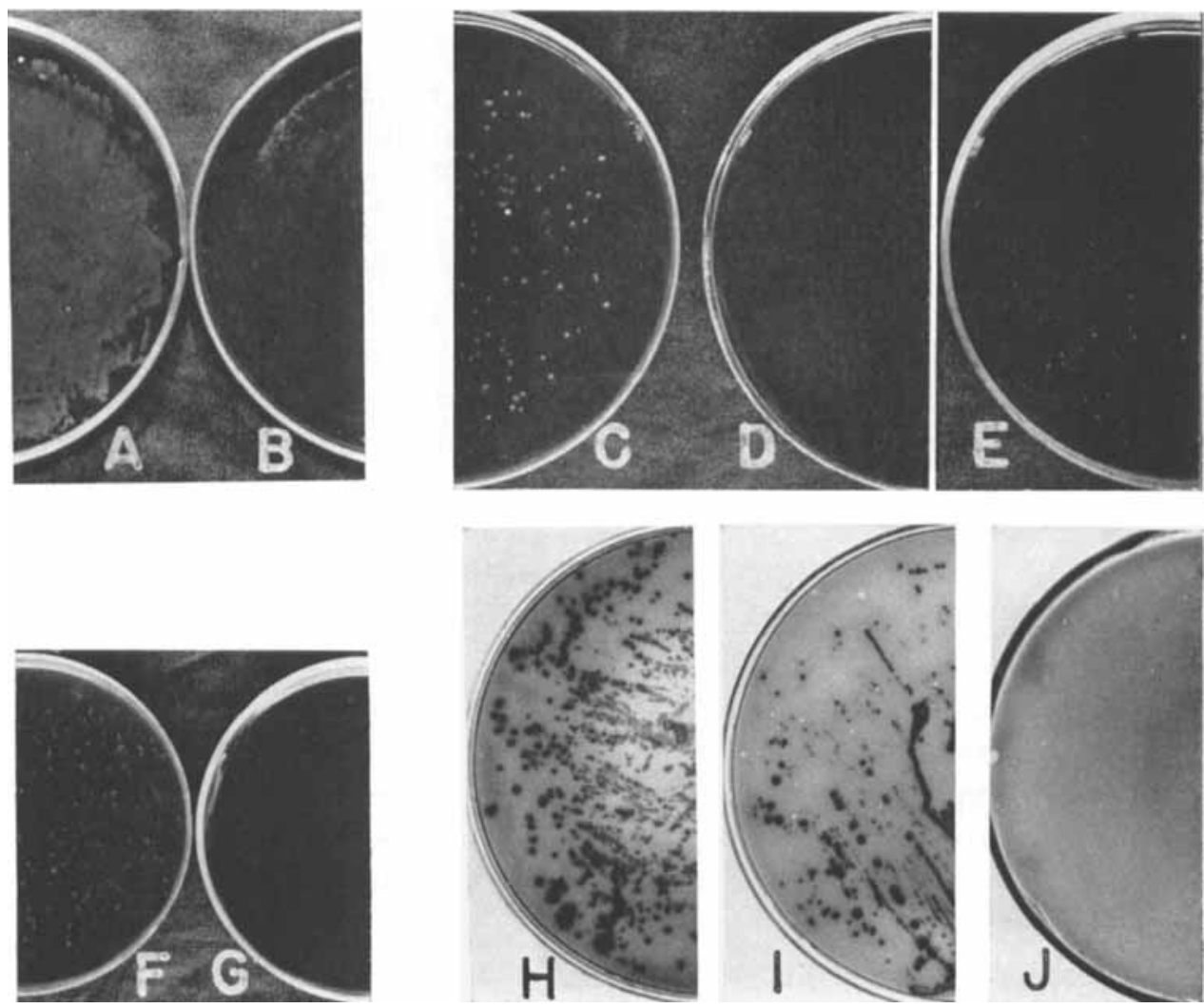

Figure 1

In the next series of exposures a lower pressure of oxygen ( $2650 \mathrm{~mm}$. $\mathrm{Hg}$ in a total barometric pressure of $3250 \mathrm{~mm}$. $\mathrm{Hg}$ ) was employed and the plates were seeded less densely than those of the first series. The result of exposure of these plates to this lower pressure was essentially the same as that of the first series. The contrast between the good growth on the control plates and the complete absence of growth on the test plates after a 24-hour exposure to this pressure is shown in 
figures 1, C and D. A subsequent exposure of these same test plates to control conditions for 24 hours indicated that although most of the organisms had been killed by the exposure to high oxygen pressure some had survived and grew after their return to control conditions (fig. 1, E).

The same results were again obtained with a pressure of approximately $1800 \mathrm{~mm} . \mathrm{Hg}$ (a total pressure of $2400 \mathrm{~mm} . \mathrm{Hg}$ ) and even with oxygen pressure as low as $900 \mathrm{~mm} . \mathrm{Hg}$ (total pressure of $1500 \mathrm{~mm}$. $\mathrm{Hg}$ ) there was complete inhibition of growth as shown in G, figure 1 . However, in oxygen at atmospheric pressure $(750 \mathrm{~mm}$. $\mathrm{Hg})$ with a trace of carbon dioxide the growth was little if any different from that of the control. It would appear therefore that the complete inhibitory action of oxygen at increased pressures is lost at oxygen pressures just below $900 \mathrm{~mm}$. Hg.

In order to determine whether perchance pressure of itself might not have been responsible for the inhibitory action described above, several experiments were carried out in which plates seeded with pneumococcus type I were exposed to room air at total pressures of 2750 and $4250 \mathrm{~mm}$. $\mathrm{Hg}$ for 24 hours. The luxuriant growth of the organisms under these pressures (fig. 1, H and I) indicate that the complete inhibition of pneumococcus type I resulting from its exposure to oxygen at high barometric pressures is not due to a pressure effect per se. It is noteworthy, however, that while the growth of those organisms exposed to the higher air pressure $(4250 \mathrm{~mm}$. $\mathrm{Hg}$ ) was good, the colonies were somewhat fewer in number and more scattered than those of either the control, or the plate exposed to the lower air pressure of $2750 \mathrm{~mm}$. $\mathrm{Hg}$. This result suggests that at an air pressure of $4250 \mathrm{~mm}$. $\mathrm{Hg}$ the partial pressure of oxygen had reached a point $\left(850 \mathrm{~mm} . \mathrm{Hg}^{3}\right)$ where it had just begun to exert an inhibitory action but was insufficient to completely arrest growth.

There is convincing evidence in the above results that many pneumococcus type I organisms are killed by exposure to oxygen at pressure of $2650 \mathrm{~mm}$. $\mathrm{Hg}$ for 24 hours, but since some organisms so exposed were viable when returned to control conditions it seemed advisable to determine whether higher pressures of oxygen might not kill all the pneumococci. To this end a number of plates were sceded with pneumococei and exposed to oxygen pressures of $5250 \mathrm{~mm}$. $\mathrm{Hg}$ (total pressure $5752 \mathrm{~mm} . \mathrm{Hg}$ ) for 24 hours. This treatment not only completely arrested all growth as might be expected from foregoing results, but also must have killed all the organisms since none of these plates showed the 
slightest indication of growth after they had been returned to control conditions for 36 hours (fig. $1, J$ ).

\section{DISCUSsION}

It has been reported (Schlayer, '36) that the oxygen consumption of pneumococci at atmospheric pressure is determined to very large degree by the oxygen tension to which the organisms are exposed and that their optimal oxygen tension is $152 \mathrm{~mm}$. Hg. The decreased oxygen consumption of these organisms at higher oxygen tensions (up to 760 $\mathrm{mm} . \mathrm{Hg}$ ) is reminiscent of the lowered oxygen consumption which occurs in mammals exposed to oxygen at several atmospheres pressure. This decrease in the oxygen consumption of animals has been attributed in part to the increased tissue and blood acidity arising from an accumulation of carbon dioxide consequent upon the non-reduction of oxyhaemoglobin which obtains under these conditions (Bean, '29, '31). But a direct depressant action of oxygen at high barometric pressure on isolated, intestinal smooth muscle, cardiac tissue and striated muscle has been also demonstrated (Bean and Bohr, '40, '38) and one may reasonably assume that such depression in activity would be attended by an equally prominent drop in oxygen consumption. Interestingly enough there is evidence that this depression in activity may be due to "anoxic" effects of oxygen at high pressures. This seemingly paradoxical relationship in which oxygen at high barometric pressures gives rise to effects simulating those of low oxygen administration has been referred to as "hyperoxic anoxia" and is attributed to a poisoning of respiratory enzymes. One wonders then if perchance the decreased oxygen consumption (Schlayer, '36), the inhibition of growth and the death of pneumococcus type I as induced in our experiments by oxygen at increased barometric pressure, might not also be explained as due to an "hyperoxic anoxia."

The administration of relatively small amounts of carbon dioxide to an animal breathing oxygen at high barometric pressure induces a much more pronounced response than a similarly small amount administered to the same animal breathing air or oxygen at atmospheric pressure (Gesell, '23). This increased response to carbon dioxide may without doubt be adequately explained as being due to the non-reduction of haemoglobin described above, but in addition it may be that the direct toxic action of oxygen on cells is enhanced by the presence of carbon dioxide, as the experiments of De Lavallée (1898) concerning the effects of carbon dioxide at increased pressure on micro-organisms suggest. 
Although pneumococcus is only moderately sensitive to peroxide (Macleod, '30) its accumulation in large amounts might suffice to inhibit and kill the organism. It may be justifiable then to speculate on the possibility that the inhibitory action of oxygen at high pressure on pneumococcus is due to an excessive accumulation of peroxide consequent upon the combination of high oxygen pressure, the active liberation of hydrogen by this organism and the absence of catalase which destroys peroxide. But dehydrogenase which plays an important role in dehydrogenation and the formation of peroxide, appears-at least in tissue extracts-to be inactivated by oxygen at high pressure (Bohr and Bean, '40), which event would make it less likely that the inhibition of pneumococcus by high oxygen pressures is due to excessive peroxide formation.

The similarity between the effects induced by oxygen at high pressure and by $\mathrm{NaCN}$ administration on isolated tissue makes it probable that oxygen at high pressure, and cyanide, which poisons cytochromes, have a common point of attack on the respiratory enzyme system of tissue cells. But that can be only a part of the story. The fact that oxygen at high pressure proved to be so profoundly inhibitory and even lethal to primitive cellular forms as the pneumococcus, while cyanide administration does not appreciably affect this organism (Burnet, '27) or its oxygen consumption (Schlayer, '36), demonstrates conclusively that the toxic action of oxygen at high pressure is not limited simply to a mimicing of the toxic action of cyanide. Moreover, if oxygen at high pressure poisons enzymes in micro-organisms which are immune to cyanide one may justifiably assume that it would similarly poison cyanide immune enzymes in mammalian tissue. It appears then that while the direct toxic action of oxygen at high pressure on mammalian tissue simulates that of cyanide it may in addition involve enzymes other than those attacked by cyanide. In further support of this contention is the finding mentioned above that dehydrogenase of mammalian tissue is inactivated by oxygen at high pressures. So far as the respiratory enzyme system of pneumococcus type $I$ is concerned one must conclude it is quite different from that of tissue cells and that the point attacked by oxygen at high pressures may very well differ from that affected in tissue cells.

In connection with the question of "anoxic" effects of oxygen at high barometric pressures, the results of one series of our experiments merits special attention because it introduces a consideration of the possible action of oxygen at high barometric pressures on anaerobic organisms which resemble pneumococci in possessing a low sensitivity 
to cyanide. In this particular series the examination of the plates which had been seeded with a supposedly pure culture of pneumococcus type I and which had been exposed for 24 hours to oxygen at $3650 \mathrm{~mm}$. $\mathrm{Hg}$ (a total barometric pressure of $4200 \mathrm{~mm}$. $\mathrm{Hg}$ ) revealed that while the pneumococcus had been completely inhibited by such exposures there were small gas bubbles throughout the media itself. The control plates showed only a good growth of pneumococcus. These results indicate that not only had there been a contamination of the media by an anaerobe, but also, strangly enough, that the growth of these anaerobes was facilitated rather than inhibited by oxygen at 4.5 atmospheres pressure. Such unexpected facilitation of growth of an anaerobe might conceivably have been due to the establishment of an "hyperoxic anoxia" by a poisoning of respiratory enzymes in the media and organisms themselves. Unfortunately this contaminant was not cultured so that additional confirmatory evidence concerning the possible facilatory effect of oxygen at high pressure on this anaerobe is wanting. Tentative conclusions on this point therefore can be accepted only with some degree of reservation.

If some anaerobes do grow at high barometric pressures of oxygen but fail to grow in air or oxygen rich environments at atmospheric pressure, it would appear that their failure to grow in air or oxygen rich environments at atmospheric pressure, is conditioned by the presence of activated oxygen rather than molecular oxygen. The absence of activated oxygen in oxygen at high barometric pressures and the resultant facilitation of growth of anaerobes might be due to the oxygen poisoning of the oxygen activators-i.e., the oxidase system. This would fall in line with the finding (Burnet, '27) that growth of strict anaerobes is not interfered with by KCN poisoning of the oxidase and that some facultative anaerobes become obligatory anaerobes by $\mathrm{KCN}$ treatment.

In comparing the effects of oxygen at high barometric pressure on protozoa (Cleveland, '25) and pneumococcus one is impressed by the greater susceptibility of the protozoa. This difference in susceptibility may well be due to a difference in the enzyme systems of the two organisms but it is not unlikely that structural differences are also responsible-especially since the pneumococcus is enveloped in capsule which may offer some barrier to oxygen penetration.

SUMMARY

1. The growth of pneumococcus type I was found to be completely inhibited by exposure for 24 hours to oxygen at pressures as low as 
$900 \mathrm{~mm} . \mathrm{Hg}$. At somewhat higher pressures many of the organisms were killed and none survived an exposure to oxygen at $3650 \mathrm{~mm} . \mathrm{Hg}$ pressure.

2. The possibility that this lethal action of oxygen may have been due to impaired oxidations induced by a poisoning of respiratory enzymes by oxygen at high pressure, was discussed. The site of this toxic action of oxygen on the respiratory enzyme system of pneumococcus differs from its point of attack on tissue cells.

3. The lethal action of oxygen at high pressures on pneumococcus as demonstrated in these experiments, contrasted with the reported absence of any such effects of cyanide on these organisms, supports the conclusion that although the toxicity of oxygen at high pressure may mimic that of cyanide in mammalian tissue it is not necessarily limited to that specific action but attacks enzyme systems on a broader front.

I wish to express my appreciation to Prof. M. H. Soule and Mr. Dodd who so kindly provided the seeded plates used in these experiments.

\section{LITERATURE CITED}

BeaN, J. W. 1929 Effects of high oxygen pressure on blood acidity, oxygen consumption, volume flow of blood and pulmonary ventilation. Proc. Soc. Exp. Biol. Med., N. Y., vol. 26, p. 832 .

1931 Effects of high oxygen pressure on carbon dioxide transport on blood and tissue acidity, and on oxygen consumption and pulmonary ventilation. $J$. Physiol., vol. 72, p. 27.

BEAN, J. W., AND D. F. BoHR 1938 High oxygen effects on isolated striated muscle. Am. J. Physiol., vol. 124, p. 576.

1940 Anoxic effects of high oxygen pressure on smooth muscle. Am. J. Physiol., vol. 130, p. 445 .

BOHR, D. F., AND J. W. BEAN 1940 Dehydrogenase inactivation in oxygen poisoning. Am J. Physiol., vol. 131, p. 388.

Burnet, F. M. 1927 The action of cyanides on bacteria. J. Bact. and Path., vol. 30, p. 21.

Cleveland, L. R. 1925 Toxicity of oxygen for protozoa in vivo and in vitro; animals deformated without injury. Biol. Bull., vol. 48, p. 454.

D'Arsonval 1891 Emploi de l'Acide Carbonique liquefée pour la filtration des liquides organiques. Compte R. Acad. Sci., Paris, vol. 112, p. 667.

DE LavalléE, H. 1898 Neues verfahrender Milch Konservierung. Mileh Zeitung no. 30, p. 472 .

Geseld, R. 1923 On the chemical regulation of respiration. Am. J. Physiol., vol. 66, p. 5.

Macleod, J. W. 1930 Bacterial Respiration; a System of Bacteriology, vol. I, Med. Res. Council Great Britain, p. 263.

Rockwell, G. E. 1923 The influence of carbon dioxide on the growth of bacteria. J. Inf. Dis., vol. 32, p. 98.

Schlayer, C. 1936 The influence of oxygen tension on respiration of pneumococeus type I. J. Bact., vol. 31, p. 181.

Soule, M. H. 1928 Gas Metabolism of Bacteria: The Newer Knowledge of Bacteriology and Immunology, Univ. of Chicago Press, p. 250. 